\title{
Gender Differences In Students' Ethical Impressions Of Questionable Marketing Practices
}

Richard A. Bernardi, (E-mail: rbernardi@rwu.edu), Roger Williams University Christopher R. Shepherd (E-mail: shep024@ hotmail.com), Roger Williams University Jillian L. Woodworth (E-mail: jw0699@alpha.rwu.edu), Roger Williams University

\begin{abstract}
In this study, we test the theory that female business majors are more sensitive than male business majors to the ethical issues in advertising promotions. We also examine whether or not business majors are as sensitive as liberal arts majors. Our sample is made up of 218 students from the Northeast area of the US. To measure ethical sensitivity in marketing situations, the participants responded to six scenarios developed from actual news data. The results indicate that female students and female business majors were more sensitive to potentially unethical advertising than male students. We also found that liberal arts students were more sensitive to ethical issues than their counterparts in business schools.
\end{abstract}

\section{Introduction}

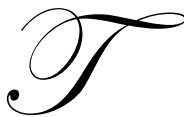

he news always appears to have some business or another under investigation for it's unethical practices (Firestone, Tobacco industry, advertising to children, etc.). Business ethics made headlines in the scandals of the early 1960's (Beltramini, et al., 1984). Companies such as Firestone with their tire recall and Microsoft with their anti-trust lawsuit companies are still wrestling with ethical issues today. There will always be companies and individuals that take advantage of the goodwill of others to make a profit (Bartlett, 2000). Many consumers are familiar with the Ford Pinto scandal and believe corporations are just faceless organizations that only care about turning a profit (Hoffman and Moore, 1984).

On August 10, 1978, a tragic automobile accident occurred on U.S. highway 33 near Goshen, Indiana. Sisters Judy and Lynn Ulrich (ages 18 and 16 respectively) and their cousin Donna Ulrich (age 18) were struck from the rear in their 1973 Ford Pinto by a van. The gas tank of the Pinto ruptured, the car burst into flames, and the three teenagers were burned to death.

Wimbush (1999) and Finn (1995) believe that individuals can influence an organization's ethical standards and culture. For example, Gales and Kesner (1994), Daily and Schwenk, (1996), and Hambrick and D'Aveni, (1992) believe that bringing in new directors will help change a corporation's image and performance. Such changes have brought more women and minorities into executive positions in the upper levels of the corporate structure (Heilman, 1997). Maier (1997) believes that elevating women's position and influence in organizations could have a drastic effect on the ethics of business. In 1973, only nine percent of the firms reported an ethnic minority member on their boards (Ferry, 1999). By 1988, 55 percent of these firms reported minority representation on their boards. Finally, in 2002 (1973), 85 (11) percent of all boards reported at least one female director (Bernardi et al., 2002; Ferry, 1999).

This research examines the ethical sensitivity of a variety of majors to determine if there are perceptual differences between those who initiate advertising campaigns and those who view these campaigns (i.e., whether busi

Readers with comments or questions are encouraged to contact the authors via email. 
ness majors are more sensitive than other majors). We also test whether women are more sensitive to ethical issues than men to advertising promotions.

\section{Literature Review}

\section{Business versus Liberal Arts Majors}

Beltramini et al. (1984) and Peterson et al. (1991) find that business majors are equally concerned about ethical values in comparison with liberal arts and science majors. McNichols and Zimmerer (1985) found that there were no significant differences between the ethical perceptions of business majors and other majors. Ten years after the Beltramini et al. study, Peterson, et al. asked the same questions of the current population of college students. Their findings replicated the earlier findings with the exception that Peterson et al. (1991) note that the students' concern about ethics had increased over the ten-year period. However, in a later study, Duizend and McCann (1998) note that students' propensity to act unethically depends on the situation. In a study using marketing dilemmas, Malinowski and Berger (1996) found only one significant difference in the ethical estimates of business and other students in marketing dilemmas. This leads to our first hypothesis (all hypotheses are stated in their null form):

H1: The ethical ratings of marketing campaigns will not be different for business and liberal arts students.

\section{Gender Differences}

Schminke (1997) notes that men and women do not differ in their Ethical Theoretic Aptitudes. However, Smith and Oakley (1997) found that female students were more ethically concerned if the issues include social concerns. These authors also note that, when the issue related to rule based considerations, gender differences were not present. Beltramini et al. (1984) and Peterson et al. (1991) report that female students were consistently more concerned about ethical issues. Malinowski and Berger (1996) found that female students responded more ethically to their marketing dilemmas than did their male counterparts. Maier (1997) speculated on the potential impact of women on the decision process using the Challenger incident as an example. In this situation, men decided to continue the launch rather than delaying the launch to repair a deteriorating propulsion system. This leads to our second and third hypotheses:

H2: The ethical ratings of marketing campaigns will not be different for male and female students.

H3: The ethical ratings of marketing campaigns will not be different for male and female business majors.

\section{Differences by Level}

Our study also examines the ethical sensitivity of students as they progress in their college education. Our thought in this part of the study is that students should be more sensitive to problems because ethics should be integrated throughout their curriculum (Karcher, 1996). Shannon and Berl (1997) examined the issue of teaching ethics. Their study indicates that 63 percent of adults were not satisfied with the ethical standard of individuals' values in the USA. Andrews (1989) attributes this feeling to the lack of ethics courses universities offer to the undergraduate students who are going to be faced with ethical problems in the workplace. Colleges and universities have responded to the business community's concerns by increasing their ethics course offerings (Collins and Warick, 1995). However, while Glenn (1992) found that business and society courses have a positive effect on students' ethical judgments, Kavathatzopoulos (1991) found that undergraduate business ethics courses did not appear to carry over into students' professional lives. Kavathatzopoulos also found that corporate ethics training affected employees actions in work related situations.

Duizend and McCann (1998) suggest that students' propensity to act unethically depends on the situation. Consequently, students may be more sensitive to the implied ethical implications in a familiar environment. Bernardi et al. (2001) found that by using scenarios relating to students' educational environment elicited significant indicators of their ethical behavior. While scores on the Defining Issues Test (Rest, 1979a) did not relate to students' 
academic honesty (Lanza-Kaduce and Klug, 1986; Malinowski and Smith, 1985; Ponemon, 1992), scores on an instrument based on academic environment were significantly associated with their academic honesty (Bernardi et al., 2001). Consequently, we believe that seniors should be more sensitive to ethical dilemmas embedded in scenarios than freshman because they should be exposed to ethical issues through their business courses. Thus our final hypothesis is:

H4: The estimates of how ethical the advertising campaigns are will not be differ by the students' exposure to the cumulative effect of business courses (i.e., year in college).

\section{Subjects And Measures}

Questionnaires including the six scenarios were sent out to marketing professors at universities in the New England area. We asked these instructors to administer the questionnaire to their classes. The sample of 218 students is made up of business and liberal arts majors as shown in Table $1 .^{1}$

\begin{tabular}{|lccc|}
\hline & $\begin{array}{c}\text { Table 1 } \\
\text { Sample Demographics }\end{array}$ & & \\
\hline Majors & Males & Females & Total \\
\hline Business majors & 59 & 48 & 107 \\
Liberal Arts majors & 40 & 76 & 116 \\
Overall Totals & 99 & 124 & 223 \\
\hline
\end{tabular}

The research process began with the creation of six individual marketing related scenarios (Appendix). These scenarios were created using actual marketing dilemmas that had been featured in recent newspaper articles. To insure the scenarios were relevant to a marketing context, two marketing professors reviewed the six scenarios. Five of the six scenarios deal with ad campaigns or timing that are based on questionable practices. The sixth scenario is a general management scenario that is used as control to determine whether there is any difference in responses if the question is not a marketing scenario.

Rest (1979b) uses a four-step model to explain ethical decision-making: (1) recognizing an ethical dilemma; (2) evaluating the alternatives; (3) making a decision; and making a decision; and (4) acting on the decision. We asked participants to rate their feelings to four questions following each dilemma using a seven-point Likert scale. The scale coded "One" as the most unethical response and "Seven" as the most ethical response. These four questions recorded the participants' concerns about:

1. whether the practice was ethical (Step 1: recognizing the dilemma);

2. $\quad$ how unethical was the practice (part of Step 1);

3. whether they agreed with the practice (Step 2: evaluating the alternatives); and

4. $\quad$ what would they do (Step Three: making a decision).

As part of this research, we use the average response to the four questions in each of our six scenarios to evaluate the first three steps in Rest's model. This procedure follows Rest's evaluation of the scoring of the Defining Issues Test (Rest, 1979a). To evaluate this procedure, we sequentially eliminated one of the questions from the data set for each six scenarios; this examination indicated that the average was not significantly affected by the responses to any question. We also evaluated the subjects' responses to the six scenarios using Cronbach's alpha (1951). Alphas in the 70s to 80s are considered to be acceptable by most researchers. The results of the test show a reliability of .72 for the six scenarios.

\section{Data Analysis}

Overview

It is important to remember that lower (higher) average rankings are indicative of less ethical (more ethical) student perceptions of the marketing campaign. Overall, students viewed the practices in scenarios one and two as the least ethical and the practice of advertising a new major well ahead of the construction date of the required facili- 
ties to support the major as the least offensive (Table 2). Students had only slightly lower views of the "Made in America" and "Way to an A" campaigns. Surprisingly, marketing adult products during times when children were the primary viewers was not perceived as being unethical.

Table 2

Comparing Responses By Major

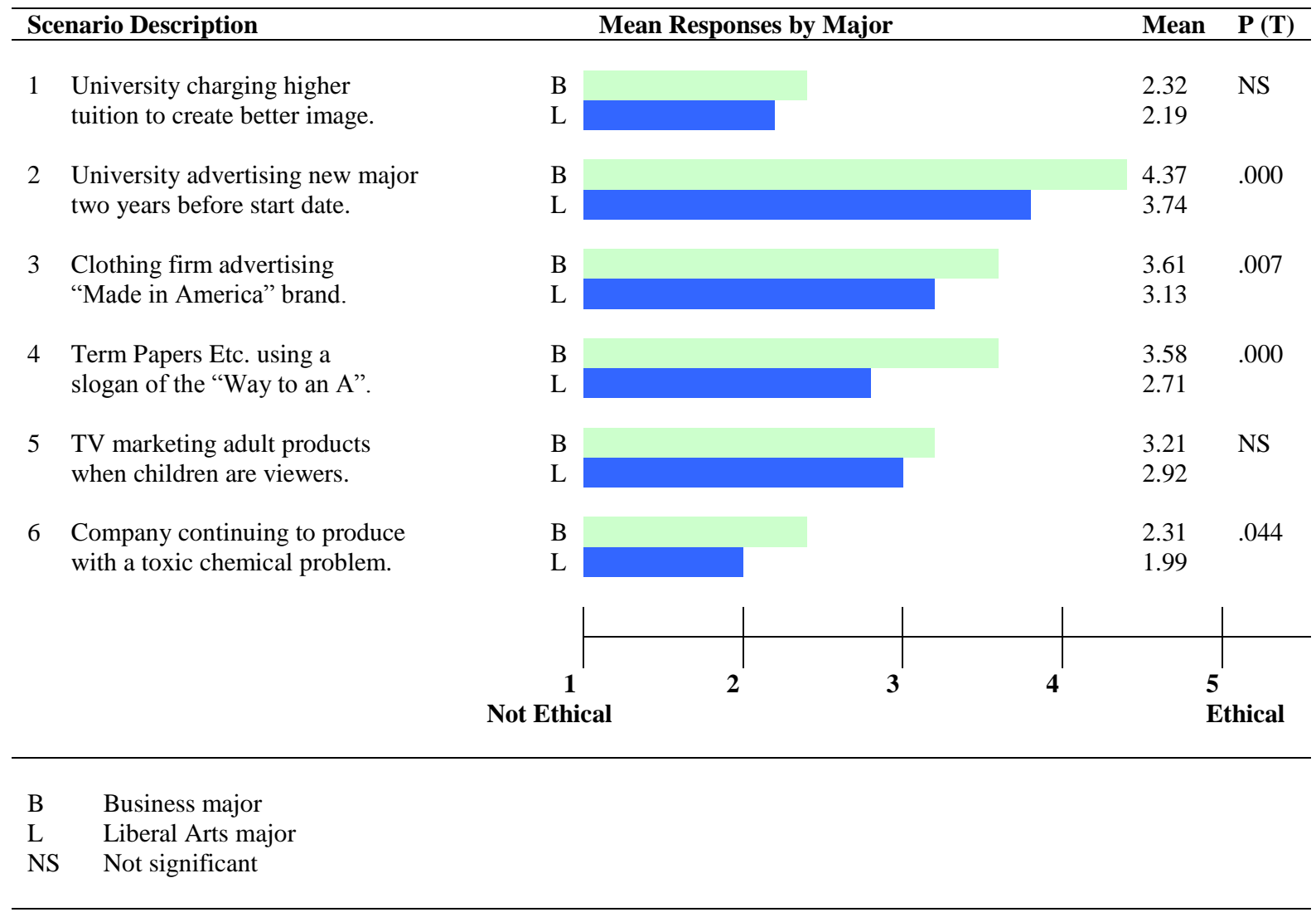

\section{Research Hypotheses}

In this part of the analysis, we examine the differences between liberal arts and business majors (H1). The data in Table 2 show the average responses to the six scenarios by major. Our analysis indicates that business majors believed that the actions in four of the scenarios were more ethical than liberal arts majors. These scenarios were the university advertising a new major (2), the "Made in America" scenario (3), firm selling term papers (4) and the company with toxic chemical problems (6).

We examined the differences between male female students for the overall sample of liberal arts and business majors (H2). The data in Table 3 show the mean responses to the six scenarios by gender. There are significant differences between the responses of male and female students for five of the six scenarios. In each of these five scenarios, male students scored the scenario as more ethical than female students. Only the scenario about the university advertising a new major (2) did not show a significant gender difference. While there was not a significant difference between majors about the marketing of adult products during times when children were the primary viewers, female students found this practice less ethical than male students $(p>.000)$. 
Table 3

Comparing Responses For All Majors By Gender

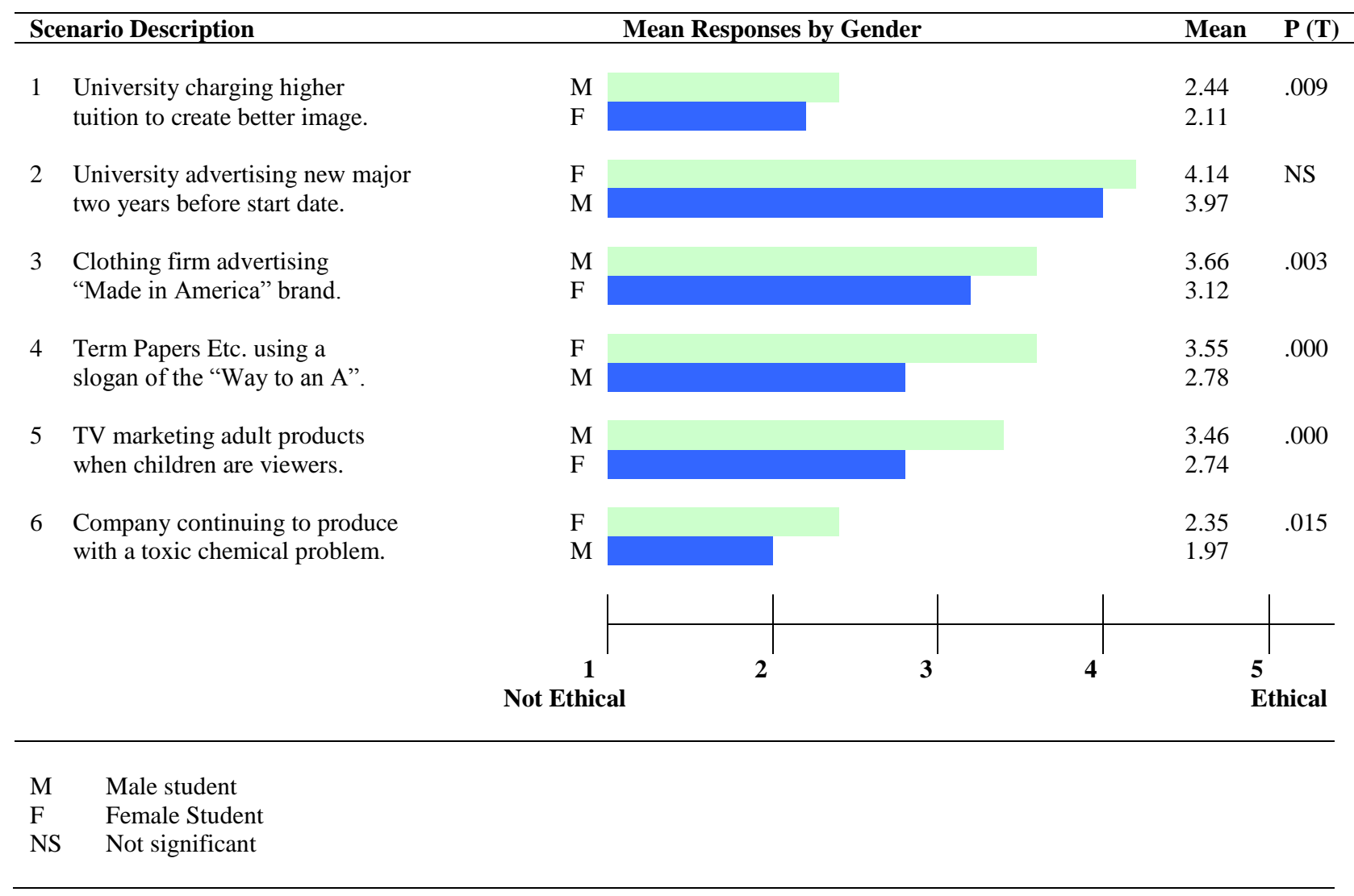

We also examined the differences between genders for business majors (H3). The data in Table 4 detail the mean responses to the six scenarios by gender for business majors. Our analysis indicates that the responses to five of the six scenarios were significantly different between male and female business majors. The only scenario that was not significantly different was the university advertising a new major (2). Consequently, the differences in the overall sample of business and liberal arts majors by gender found in hypothesis two are also present in hypothesis three for business majors. This supports prior research indicating that women are more sensitive to ethical issues.

Our final hypothesis (H4) anticipated differences between the different levels (i.e., freshmen, sophomores, juniors and seniors) of business majors. Our thought was that, if ethics is woven into the various courses in the business curriculum, sensitivity should increase from the freshman group to the senior group. Our analysis indicates that maturation was significant for the "Made in America" $(p=.05)$, Term Papers $(p=.02)$, and toxic chemicals $(\mathrm{p}=.02)$ scenarios. In these three scenarios, the responses were consistently lower as level increased (i.e., the practices were perceived as less ethical). 
Table 4

Comparing Responses For All Business Majors By Gender

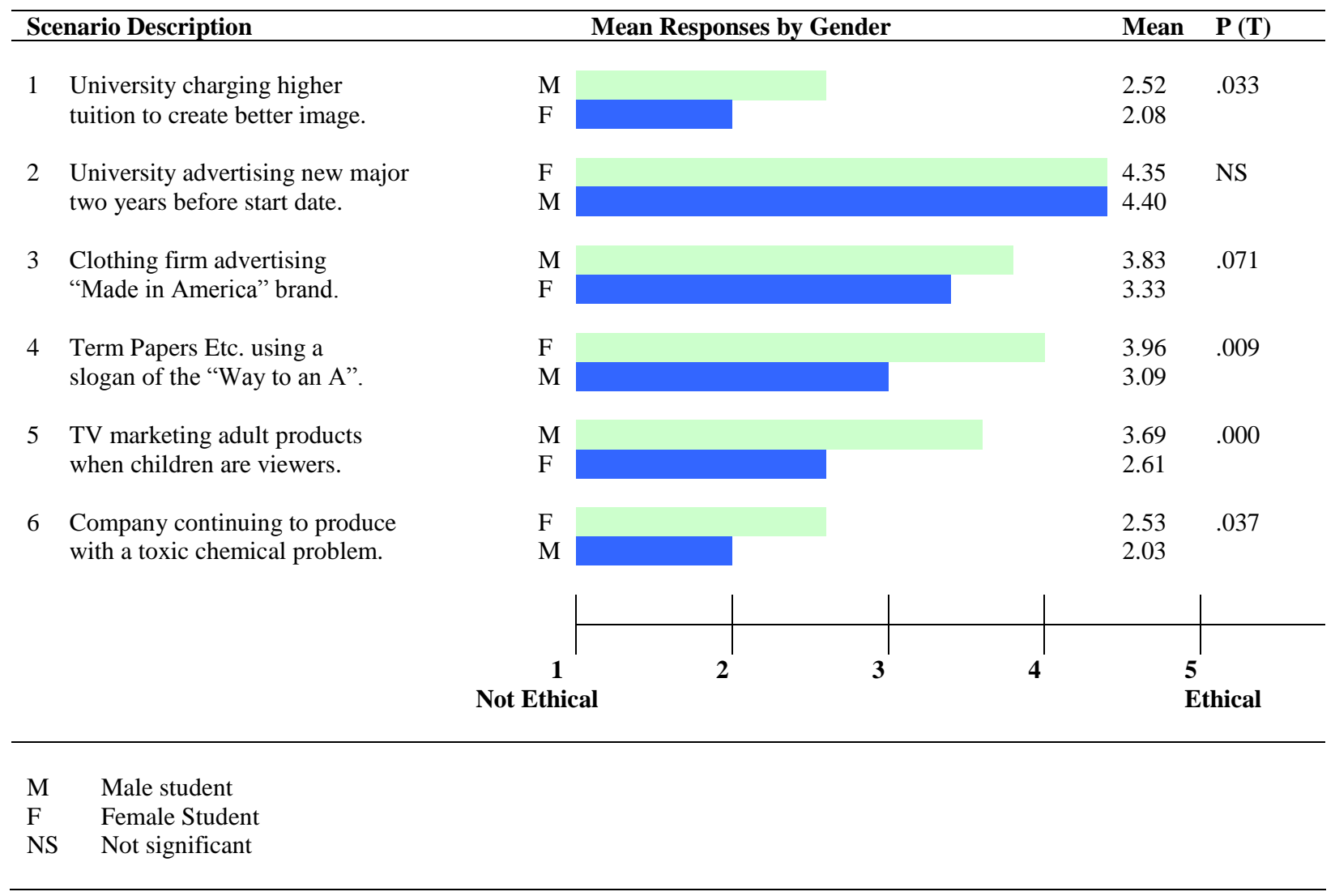

\section{Conclusions}

Our research provides additional evidence that gender plays an important role in the level of ethical sensitivity. Female students tended to be more ethically sensitive regardless of major. Our research also indicates that Liberal Arts majors have a higher degree of ethical sensitivity than business majors. It appears that the differences ethical perceptions by gender found in prior research (Beltramini et al., 1984; Malinowski and Berger, 1996; Peterson et al., 1991; Schminke, 1997; Smith and Oakley, 1997) persist in the current environment.

Our finding that business majors are not as sensitive to ethical issues as liberal arts majors is disturbing in light of Peterson et al.'s (1991) study. These authors found that the gap between business and liberal arts majors had dissipated over a seven-year period from 1984 to 1991. Our research indicates that business majors appear to be less sensitive to the ethical implications of questionable marketing issues than liberal arts students. Our data suggest the importance of the International Association for Management Education (formerly known as the American Assembly of Collegiate Schools of Business or AACSB) requirement for an ethical component in the business curriculum either as a stand-alone course or integrated throughout the curriculum for schools to become accredited (Karcher, 1996).

Our finding that ethical sensitivity increased with maturation supports this concern over a limited data set. While we did find differences, they were only present in three of the six scenarios. Our research suggests that, while some progress has been made, there is still a need to emphasize ethics across our curriculum in business. We be- 
lieve that business schools should consider requiring an ethics course as part of their core curriculum. This is especially cogent in light of the recent ethical failures in our business environment.

There are at least three limitations to our research. First, the sample was taken from five universities in the northeast and may not represent the entire population. Second, the differences we found could be the result of the scenarios we used. Finally, we averaged the four responses to each scenario.

\section{Endnote}

1. We found no differences by school; consequently, we collapsed the data by school for the remainder of the research.

\section{References}

1. $\quad$ Andrews, K. R. (1989) Ethics in Practice, Harvard Business Review, 89 (5): 99-104.

2. Bartlett, A., and Preston, D. (2000) Can Ethical Behavior Really Exist in Business. Journal of Business Ethics, 23 (2): 199-209.

3. Beltramini, R. F., Peterson, R. A., and Kozmetsky, G. (1984) Concerns of College Students Regarding Business Ethics: A Replication. Journal of Business Ethics, 10: 733-738.

4. Bernardi, R. A., Bean, D. F., and Weippert, K. M. (2002). Signaling Gender Diversity Through Annual Report Pictures: A Research Note on Image Management, Accounting, Auditing and Accountability Journal, forthcoming.

5. Bernardi, R., Metzger, R., Scofield, R., Wade, M., Reese, L., and Barnaby, G. (2001). Examining the Decision Process of Individuals Facing the Temptation to Cheat, at the American Accounting Association's Sixth Symposium on Ethics in Accounting, Atlanta, Georgia.

6. Collins, D., and Warick, S. L. (1995). Business and Society/Business Ethics Courses. Business and Society, 34 (1): 51-89.

7. Cronbach, L. J. (1951). Coefficient Alpha and the Internal Structure of Tests. Psychometrika, 16, 297-334.

8. Daily, C., and Schwenk, C. (1996).Chief executive officers, top management teams, and boards of directors: congruent or countervailing forces? Journal of Management, 22: 185-208.

9. Duizend, J., and McCann, G. K. (1998) Do Collegiate Business Students Show a Propensity to Engage in Illegal Business Practices? Journal of Business Ethics, 17: 229-238.

10. Ferry, R. M. (1999). "Boardrooms yesterday, today and tomorrow", Chief Executive, March, pp. 44-47.

11. Finn, D. W. (1995) Ethical Decision Making in Organizations: A Management Employee-Organizational Whistleblowing Model. Research on Accounting Ethics, 1: 291-313.

12. Gales, L., and Kesner, I. (1994). An analysis of board of director size and composition in bankrupt organizations, Journal of Business Research, 30: 271-282.

13. Glenn, J. R. (1992) Can a Business and Society Course Affect the Ethical Judgment of Future managers? Journal of Business Ethics, 11, 217-223.

14. Hambrick, D., and D'Aveni, R. (1992). Top team deterioration as part of the downward spiral of large corporate bankruptcy, Management Science, 38: 1445-1466.

15. Heilman, M. E. (1997) Sex Discrimination and the Affirmative Action Remedy: The Role of Sex Stereotypes. Journal of Business Ethics, 16: 877-889.

16. Hoffman, W. M., and Moore, J. M. (1984) Business Ethics : Readings And Cases In Corporate Morality / W. Michael Hoffman, Jennifer Mills Moore

17. Kavathatzopoulos, L. (1991) Morality can be Taught, European Business Ethics Newsletter, 5.

18. Karcher, J. (1996). Auditors' Ability to Discern the Presence of Ethical Problems. Journal of Business Ethics, 15: 1033-1050.

19. Lanza-Kadce, L., and Klug, M. (1986). Learning to Cheat: The Interaction of Moral Development and Social Learning Theories. Deviant Behavior, 7: 243-259.

20. Maier, Mark (1997) "Gender Equity, Organizational Transformations and Challenger" Journal of Business Ethics, 16: 943-962.

21. Malinowski, C., and Berger, K. A. (1996) Undergraduate Student Attitudes About Hypothetical Marketing 
Dilemmas, Journal of Business Ethics, 15: 525-535.

22. Malinowski, C. L., and Smith, C. D. (1985). Moral Reasoning and Moral Conduct: An Investigation Prompted by Kohlberg's Theory. Journal of Personality and Social Psychology, 49: 1016-1027.

23. McNichols, C. W., and Zimmerer, T. W. (1985) Situational Ethics: An Empirical Study of Differentiators of Student Attitudes, Journal of Business Ethics, 4: 175-180.

24. Peterson, R. A., Beltramini, R. F., and Kozmetsky, G. (1991) Concerns of College Students Regarding Business Ethics. Journal of Business Ethics, 3: 195-200.

25. Ponemon, L. A., (1992). Auditor Underreporting of Time and Moral Reasoning: An Experimental Lab Study. Contemporary Accounting Research, 9: 71-189.

26. Rest, J. R. (1979a). Development in Judging Moral Issues. Center for the Study of Ethical Development, University of Minnesota, Minneapolis, MN: University of Minnesota Press.

27. Rest, J. R. (1979b). Defining Issues Test. Center for the Study of Ethical Development, University of Minnesota, Minneapolis, MN: University of Minnesota Press.

28. Schminke, M. (1997) Gender Differences in Ethical Frameworks and Evaluation of Others' Choices in Ethical Dilemmas, Journal of Business Ethics, 16: 55-65.

29. Shannon, J. R., and Berl, R. L. (1997). Are We Teaching Ethics in Marketing? A Survey of Students' Attitudes and Perceptions. Journal of Business Ethics, 16: 1059-1075.

30. Smith, P. L., and Oakley, E. F., III, (1997) Gender-Related Differences in Ethical and Social Values of Business Students: Implications for Management, Journal of Business Ethics, 16: 37-45.

31. Wimbush, J. C. (1999) The Effect of Cognitive Moral Development and Supervisory Influence on Subordinates Ethical Behavior, Journal of Business Ethics, 18: 383-395.

\section{Appendix A \\ Research Scenarios In Marketing}

Scenario 1: After some extensive research one university found that it might be able to increase student enrollment by marking up the tuition in order to create a greater amount of prestige. The university is making this raise in tuition without making any other advancements or changes to the current facility or curriculum. The University is not planning on changing their tuition policy and will continue to make students pay more for the same education they would have got at the old price.

1. Do you consider this to be an ethical practice?

1

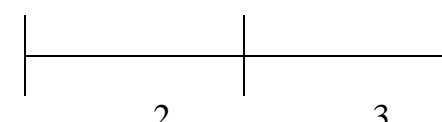

4

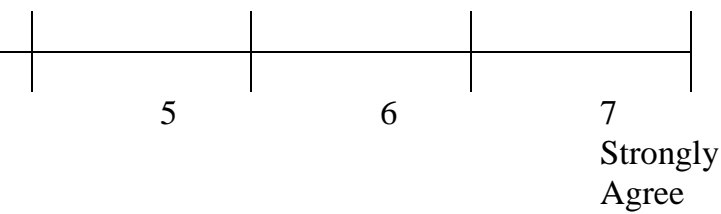

Disagree

Agree

2. How do you perceive the university's attitudes towards charging tuition?

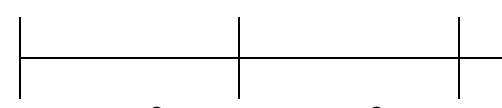

Unethical
2

3

4

5
7

Ethical 
3. Would you agree with their tuition strategy?

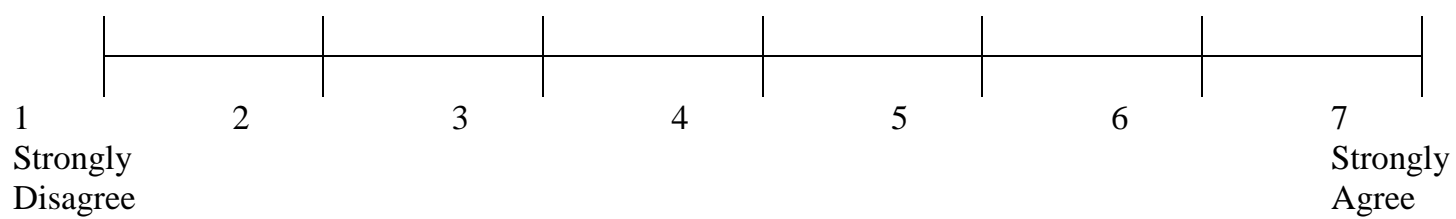

4. If you were an employee in an organization that practices this behavior in question would you continue without saying something?

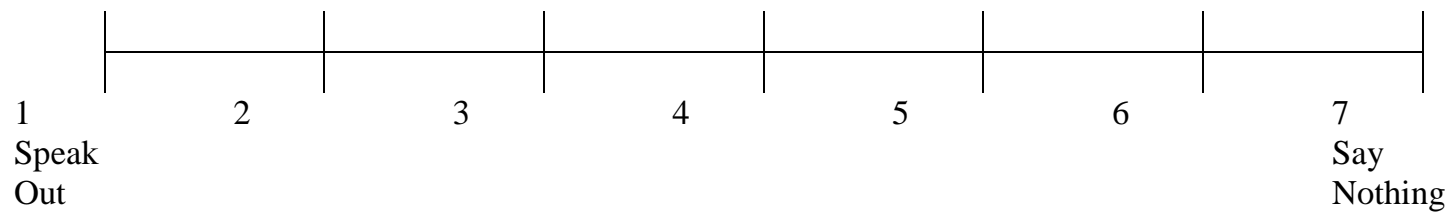

Scenario 2: A university located in northern Utah has just received a large contribution form one of its richest Alumni. The university plans to build a state-of-the-art facility for its new Air and Space major. Construction on the new facility has already begun but the facility will be completed for another two years. Admissions and the university are very excited about this great addition to their University and estimate this new major will bring in a lot of new students. Admissions have begun advertising in every video, handbook and pamphlet for the new program saying, "Construction has already begun, and it will be completed soon so reach for the stars at our university."

Scenario 3: John is the advertising manager for a clothing company that advertises their clothing as "American Made" to appeal to a target market that objects to using foreign production. However, the company only assembles the clothing in the USA and most of the materials that go into the construction are made in foreign countries. Regardless of the origin of the materials, the company will continue advertising it's clothing as "American Made".

Scenario 4: M.J. is the marketing VP for Term Papers Etc., a new web-based company that offers complete papers of all topics available for a nominal fee. This company advertises to the college market by calling themselves the "Way to the Easy Al" The company uses a disclaimer stating that the papers are to be used for research purposes only and is not to be used to replace actually doing the work. This disclaimer, however, is in very small print in a remote section of the web site. The company continues to advertise in this manner to boost profits and college student popularity.

Scenario 5: Daytime television programming in the afternoon is usually geared towards younger children and adolescents who have just come home from school. During these youth-oriented programs, advertising that clearly appeals to an adult audience is aired. As a result, children are exposed to the products and become familiar with catchy slogans and/or jingles, further promoting the adult products. This television station has no intentions of changing the time slots of their current advertising and the schedule will go on uninterrupted.

Scenario 6: Kooky Kola Company produces millions of cans of cola each day. It was recently discovered that there have been traces of a toxic chemical in the machinery used in the production of the cola. This chemical has been found to be fatal in humans if it is digested in large enough doses but the chance of anyone being severely harmed by the cola is only $2 \%$. The cost of new machinery is too much for the company right now and since it is believed that it would be very unlikely if anyone were to be harmed by the levels of the chemical found so far the company will go on with production and distribution as usual. 
Notes 